\title{
Neotropical Monogenoidea. 3. Five new species from South America with the proposal of Tereancistrum gen. n. and Trinibaculum gen. n. (Dactylogyridae: Ancyrocephalinae)
}

\author{
Delane C. Kritsky (") \\ Vernon E. Thatcher ("*) \\ Robert J. Kayton (")
}

\begin{abstract}
Five new species of Monogenoidea (Dactylogyridae: Ancyrocephalinae) are described from the gills of freshwater fishes of South America: Jainus amazonensis sp. n., Tereancistrum kerri gen. et $\mathrm{sp}$. n., and Trinibaculum braziliensis gen. et $\mathrm{sp}$. $\mathrm{n}$. (all) from Brycon melanopterus (Cope), Januacá Lake near Manaus, Amazonas, Brasil; Tereancistrum ornatus sp. $n$. from Prochilodus reticulatus Steindachner, Rio Cauca, Juanchito, Cali, Valle, Colombia; and T. parvus sp. n. from Leporinus fasciatus (Bloch), Amazon River Basin. Two new genera are proposed. Tereancistrum gen. $n$. is characterized by having spathulate acessory anchor sclerites associated with the ventral anchors. Trinibaculum gen. $\mathrm{n}$. is proposed for species with a single ventral bar, two widely separated dorsal bars, a dextroventral vagina, confluent intestinal crura, and intercecal gonads.
\end{abstract}

\section{INTRODUCTION AND METHODS}

The hosts, Brycon melanopterus (Cope) and Prochilodus reticulatus Steindachner were collected by the second author from freshwater in Brazil (June, 1978) and Colombia (January, 1972), respectively. These fish were treated and parasites collected and stored according to the procedures of Kritsky \& Thatcher (1974). Leporinus fasciatus (Bloch) was obtained frozen from Steinhart Aquarium, San Francisco, during 1968 (courtesy of Mr. R. P. Dempster). This fish was later thawed and the single specimen of Tereancistrum parvus, gen. et sp. n. was removed from the gills and mounted unstained in Gray and Wess' medium. Parasites of the former hosts were stained with Mayer's carmine or Gomori's trichrome and mounted in permount for observing internal organs. Other specimens were mounted unstained in
Gray and Wess' medium for study of sclerotized structures. Measurements of parasites were made according to the guidelines of Mizelle and Klucka (1953); all are in micrometers. Figures were prepared with the aid of a microprojector and camera lucida. Type specimens were deposited in the collections of the Instituto Nacional de Pesquisas da Amazônia (INPA), the Museu de Zoologia da Universidade de São Paulo (MZUSP), the U.S. National Museum (USNM), and the University of Nebraska State Museum (UNSM).

\section{SYSTEMATIC SECTION}

Jainus amazonensis, sp. $\mathrm{n}$. (Figs. 1-5)

Host: Matrinchã; Brycon melanopterus (Cope), Characidae.

Location: Gills.

Locality: Januacá Lake, near Manaus, Amazonas, Brasil.

Types: INPA (holotype and paratypes); MZUSP (paratype); USNM (paratypes); UNSM (paratype).

DESCRIPTION (based on 25 specimens)

Body pyriform, length 368 (316-530), greatest width 142 (82-204) in posterior half. Tegument thin, smooth. Cephalic region with apical and two well-developed lateral lobes. Head organs well developed; two in apical, one in each lateral lobe. Cephalic glands numerous, lying in two bilateral groups dorsoposterior to phorynx. Eyes 4; members of

(*) - Idaho State University, Pocatello, Idaho 83209 USA.

(*) - Instituto Nacional de Pesquisas da Amazônia, Manaus. 
anterior pair smaller, usually closer together or nearly equidistant to members of posterior pair; component eye granules small, spherical; accessory granules infrequent in cephalic area. Pharynx subspherical, 17 (14-21) in diameter; esophagus, crura obscured. Peduncle short to absent; haptor posteroventral, subtriangular, 67 (41-92) wide, 62 (31-71) long. Hook distribution of ancyrocephaline arrangement (Mizelle, 1936). Hooks 11 (9-12) long, similar; each with erect thumb, slightly curved shaft and point, shank with minute proximal enlargement; filamentous hook (FH) loop approximately $3 / 4$ shank length. Ventral anchior 14 (11-18) long, with bladelike point, short shaft, small elevation on inner surface of base; superficial root with elongate terminal extension; anchor base 10 (8-13) wide. Dorsal anchor 39 (35-42) long, with poorly developed deep root, sharply recurved point, constriction of anchor shaft near union with point; base $12(11-14)$ wide. Ventral bar 18 (13-21) long, broadly V shaped, with small medial projection. Dorsal bar 26 (24-32) long, simple, arcuate. Gonads intercecal, tandem or slightly overlapping. Testis postovarian, ovate, 36 (24-44) long, 18 (11-25) wide; vas deferens obscured by vitellaria; seminal vesicle usually large, lying in midline immediately posterior to copulatory complex; prostatic reservoir pyriform, lying ventral to seminal vesicle. Cirrus a coil of one ring, ring diameter 21 (15-29); accessory piece 23 (17-25) long, variable, flabellate distally, articulating to cirrus base. Ovary fusiform, elongate, 23 (15-31) wide, 131 (96-203) long; uterus delicate; vagina simple, sinistral; seminal receptacle lying to left of midline near anterior end of ovary, a simple dilation of duct of vagina. Vitellaria dense throughout trunk except absent in region of gonads and copulatory complex.

\section{REMARKS}

Jainus Mizelle, Kritsky and Crane, 1968, is presently restricted to the Neotropical Region and contains three other species: J. jainus Mizelle, Kritsky and Crane, 1968; J. robustus Mizelle, Kritsky and Crane, 1968; and J. hexops Kritsky and Leiby, 1972. Jairus ama-

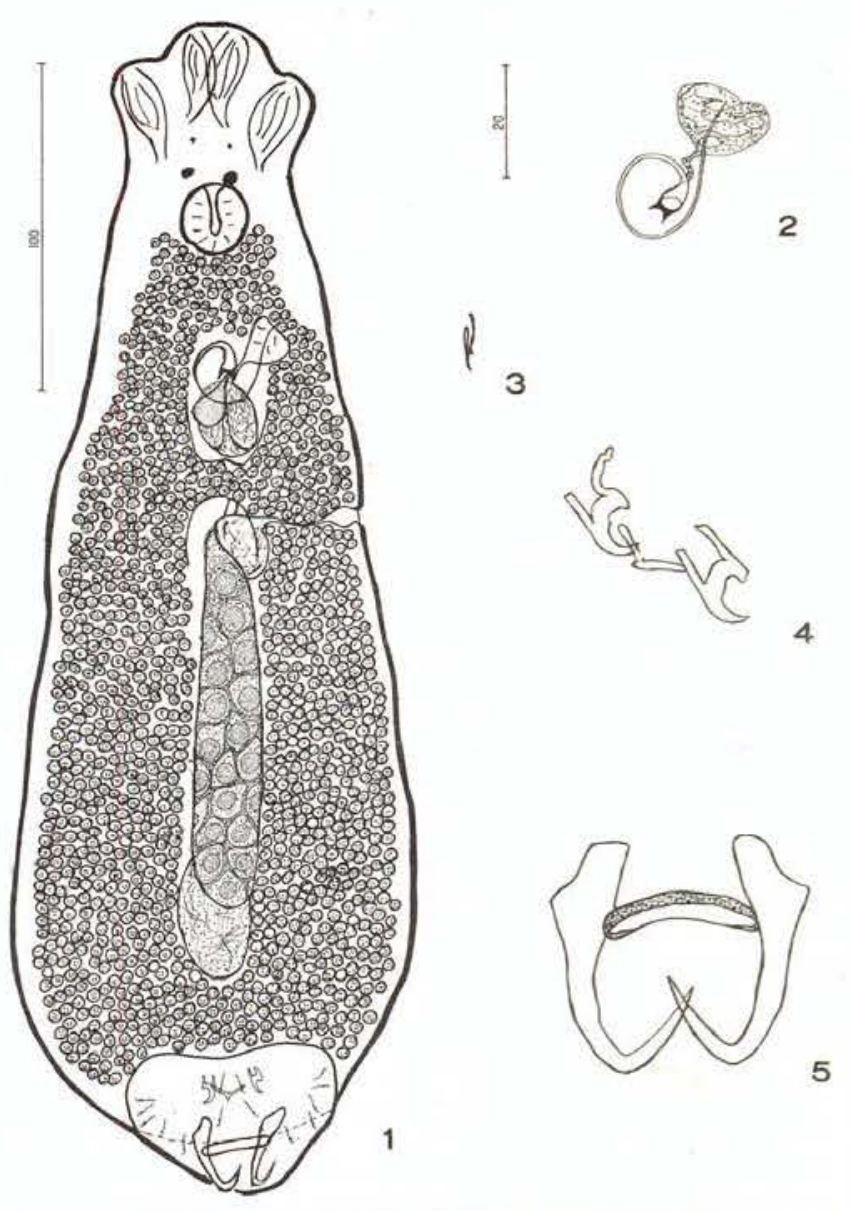

Plate I: Figures 1-5. Jainus amazonensis, sp. n. 1, whole mount (ventral). 2, copulatory complex. 3 , hook. 4 ventral anchors and bar. 5, dorsal anchors and bar. All figures are drawn to the same scale $\left(20_{\mu}\right.$ except figure $1(100 \mu)$.

zonensis sp. n. most closely resembles J. jainus, from which it differs by having an elongate terminal extension on the superficial root of the anchor base and a well-developed sinistral vagina. It is differentiated from $J$. robustus $J$. hexops by having a simple coiled cirrus and an accessory piece articulated to the base of the cirrus. The specific name indicates the river basin from which the host was collected.

Tereancistrum, gen. $\mathrm{n}$.

DIAGNOSIS

Dactylogyridae: Ancyrocephalinae. Body divisible into cephalic region, trunk, peduncle and haptor. Tegument thin, smooth. Cephalic area with three lobes. Head organs, cephalic 
glands present. One or two pairs of eyes. Pharynx muscular, glandular; esophagus bifurcating into two intestinal crura; crura confluent posterior to gonads. Gonads intercecal, tandem or slightly overlapping, testis postovarian; seminal vesicle a dilation of vas deferens. Cirrus, accessory piece present. Ovary lying near midlength; vitellaria well developed. Haptor armed with 14 ( 7 pairs) hooks, two pairs of anchors; hooks similar, with ancyrocephaline distribution (Mizelle, 1936). Ventral anchors with accessory anchor sclerite articulated to tip of superficial root; accessory sclerite with terminal spathulate portion. Dorsal, ventral bars present. Parasitic on gills of freshwater fishes.

Type species: T. kerri sp. $\mathrm{n}$.

Type host: Brycon melanopterus (Cope). Characidae.

Other species: $T$. ornatus sp. n. from Prochilodus reticulatus Steindachner; $T$. parvus $\mathrm{sp}$. n. from Leporinus fasciatus (Bloch).

\section{REMARKS}

Several ancyrocephaline genera are characterized by having additional scierotized structures or bars associated with either the dorsal or ventral anchors; namely, Ancylodiscoides Yamaguti, 1937; Bychowskyella Achmerov, 1952; Heterotesia Paperna, 1969; Mizelleus Jain, 1957; Neomurraytrema Tripathi, 1959; Neosprostonia Jain, 1959; Protoancylodiscoides Paperna, 1969; Pseudancylodiscoides Yamaguti, 1963; Silonditrema Tripathi, 1959; Unilatus Mizelle and Kritsky, 1969; and Wallagotrema Tripathi, 1959. In most of these the accessory anchor sclerites are simple, frequently represented by a small patch or irregular sclerotized structure (Ancylodiscoides, Bychowskyella, Heterotesia, Neomurraytrema, Neosprostonia, Pseudacylodiscoides, and Unilatus). Tereancistrum gen. $\mathrm{n}$. differs from these and Wallagotrema and Mizelleus by having a distinctly spathulate accessory anchor sclerite. It most closely resembles Protoancylodiscoides in the morphology of the haptor and accessory anchor sclerite, but differs dramatically in the relative position of the internal organs. In Tereancistrum the reproductive system is typically ancyrocephaline while in Protoancylodiscoides the male system is shifted significantly posteriorly in the trunk. Also, the accessory anchor sclerite in Tereancistrum is heavily sclerotized while Paperna (1969) reports it as non-sclerotized in the latter genus.

The generic name is from Greek (tere = guard + ancistrum $=$ hook) and refers to the ventral anchor and accessory sclerite configuration.

Tereancistrum kerri, sp. $\mathrm{n}$. (Figs. 6-12)

Host: Matrinchã; Brycon melanopterus (Cope), Characidae.

Location: Gills.

Locality: Januaca Lake, near Manaus, Amazonas, Brasil.

Types: INPA (holotype and paratypes): MZUSP (paratype): USNM (paratypes); UNSM (paratype).

DESCRIPTION (based on 16 specimens)

Body fusiform, length 340 (275-400), greatest width 80 (51-102) near midlength. Cephalic region with apical and two bilateral incipient lobes. Head organs, cephalic glands poorly developed. Eyes four, members of each pair equidistant; posterior pair larger; component granules elongate ovate; few accessory granules in anterior trunk and cephalic region. Pharynx subovate, 21 (20-22) wide; esophagus short to moderate. Peduncle broad; haptor subhexagonal, 93 (71-133) long, 93 (51-122) wide. Hook pairs 1, 5--16 (15-17), pairs 2 . $3,4,6,7--22$ (21-23) long; each with straight thumb, curved shaft, short point, dilated proximal half of shank; FH loop about $1 / 2$ shank length. Ventral anchor 55 (51-59) long, with broadly curved shaft and point, well-developed roots, small fold on base; tip of superficial root reflexed; base 17 (15-18) wide. Accessory anchor sclerites 50 (39-56) long, robust, with large spathulate end. Dorsal anchor 46 (43-50) 


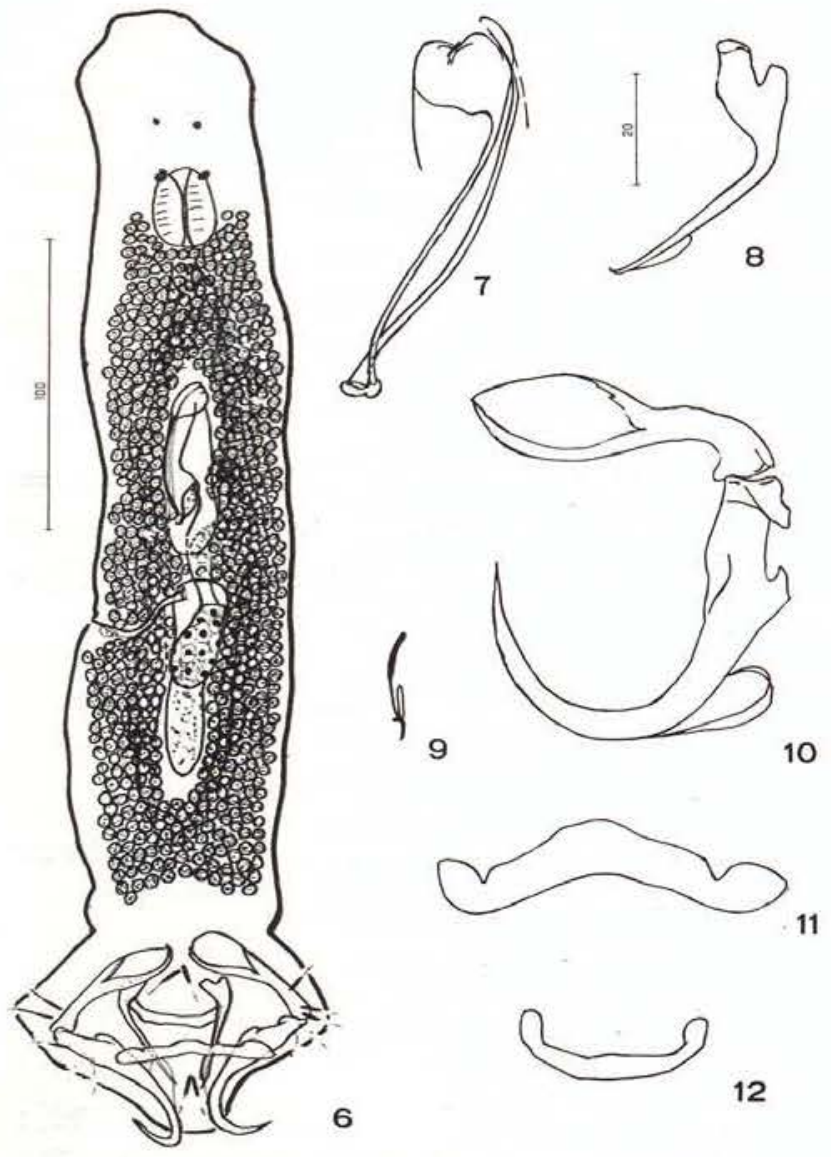

Plate II: Figures 6-12. Tereancistrum kerri, gen. et sp. n. 6, whole mount (ventral). 7, copulatory complex. 8 , dorsal anchor. 9, hook. 10, ventral anchor and accessory anchor sclerite. 11, ventral bar. 12, dorsal bar. All figures are to the same scale $(20 \mu)$ except figure 6 $(100 \mu)$.

long, with well-developed base and roots, shaft bent proximally, point attenuated to fine recurved tip; base $13(12-14)$ wide. Ventral bar 62 (54-74), long, variable, with medial and terminal enlargements. Dorsal bar simple, broadly U shaped, 33 (30-36) long. Gonads slightly overlapping. Testis elongate ovate, 27 (18-37) long, 11 (7-15) wide; vas deferens obscured; seminal vesicle lying sinistral to cirrus base; prostatic reservoir indistinct. Cirrus 61 (55-72) long, a simple tapered tube with small base. Accessory piece 63 (46-72) long, articulated with cirrus base, continuous with lightly sclerotized wall of genital atrium. Ovary pyriform, near midlength, 33 long, 13 wide; uterus delicate; vagina dextral at level of ovary, a simple sclerotized tube reflexed distally; seminal receptacle probably present as a pyriform, sperm-filled structure lying dorsal to vitelline ducts (in none of the present specimens could ducts be observed leading to or from this structure). Vitellaria scattered throughout trunk except absent in areas of gonads and copulatory complex.

\section{REMARKS}

Tereancistrum kerri $\mathrm{sp}$. $\mathrm{n}$. is the type species for the genus. It is closest to $T$. parvus $\mathrm{sp}$. $\mathrm{n}$. from which it differs by having a simple tapered cirrus, an accessory piece continuous with the sclerotized wall of the genital atrium, and in the comparative morphology of the anchors, bars, and accessory anchor sclerite (see Figs. 6-12 and 20-26). This species is named for Dr. Warwick Kerr, Director, INPA, Manaus, Amazonas, Brasil.

\section{Tereancistrum ornatus, $\mathrm{sp} . \mathrm{n}$.}

(Figs, 13-19)

Host: Prochilodus reticulatus Steindachner, Prochilodontidae.

Location: Gills.

Locality: Rio Cauca, Juanchito, Cali, Valle, Colombia.

Types: INPA (holotype and paratypes); MZUSP (paratype); USNM (paratypes); UNSM (paratype).

\section{DESCRIPTION (based on 20 specimens)}

Body elongate, fusiform, 690 (459-918) long; greatest width $130 \quad(102-204)$ near midlength or in anterior half. Cephalic lobes poorly developed; head organs well developed, two in apical, one in each lateral lobe; cephalic glands indistinct. Eyes four, one or both members of anterior pair sometimes lacking; posterior pair larger, equidistant to members of anterior pair; component granules spherical, variable in size; accessory granules rare. Pharynx subovate, 37 (31-56) wide; esophagus short. Peduncle long, moderate in width; haptor subhexagonal, 83 (71-112) wide, 65 (51-102) long. Hooks 13 (11-15) long; each with erect thumb, slightly curved shaft and point, 
small proximal enlargement of shank; FH loop about $1 / 2$ shank length. Ventral anchor robust, 39 (33-44) long, with well-developed roots, short shaft, recurved point; base 24 (22-28) wide. Accessory anchor sclerite 29 (23-33) long, robust, with small spathulate end. Dorsal anchor 43 (39-51) long, with widely divergent roots of anchor base, short shaft, straight point; base 38 (28-44) wide. Ventral bar 54 (44-61) long, with bean-shaped terminations. Dorsal bar 38 (35-46) long, $Y$ shaped; ends modified for attachment to dorsal anchors. Cirrus a tapered tube, coiled into $1 \frac{114}{4}$ rings; ring diameter 26 (22-33). Accessory piece 26 (22-33) long, variable, articulated to cirrus base. Vagina sinistral, a simple sclerotized tube. Vitellaria random throughout trunk except absent in regions of gonads and copulatory complex.

\section{REMARKS}

This species closely resembles $T$. parvus $\mathrm{sp}$. $\mathrm{n}$. in the morphology of the cirrus and ventral bar. They are easily differentiated by the comparative morphology of the anchors, dorsal bar and hooks (see Figs. 13-19 and 20-26). The specific name is from Latin (ornatus $=$ adorned).

\section{Tereancistrum parvus, $\mathrm{sp} . \mathrm{n}$.} (Figs, 20-26)

Host: Aracu, Leporinus fasciatus (Bloch), Anostomidae.

Location: Gills.

Locality: Amazon River Basin (the host was obtained from Steinhart Aquarium, San Francisco, in 1968; but was originally collected from the Amazon Basin).

Type: USNM (holotype).

\section{DESCRIPTION (based on 1 specimen)}

Body slender, fusiform, 326 long; greatest width 41 near midlength. Cephalic region with apical and two bilateral incipient lobes; head organs, cephalic glands indistinct. Eyes two, lying immediately anterior to pharynx; component granules subspherical, variable in size; accessory granules numerous throughout trunk. Pharynx subovate, 29 wide. Peduncle broad;
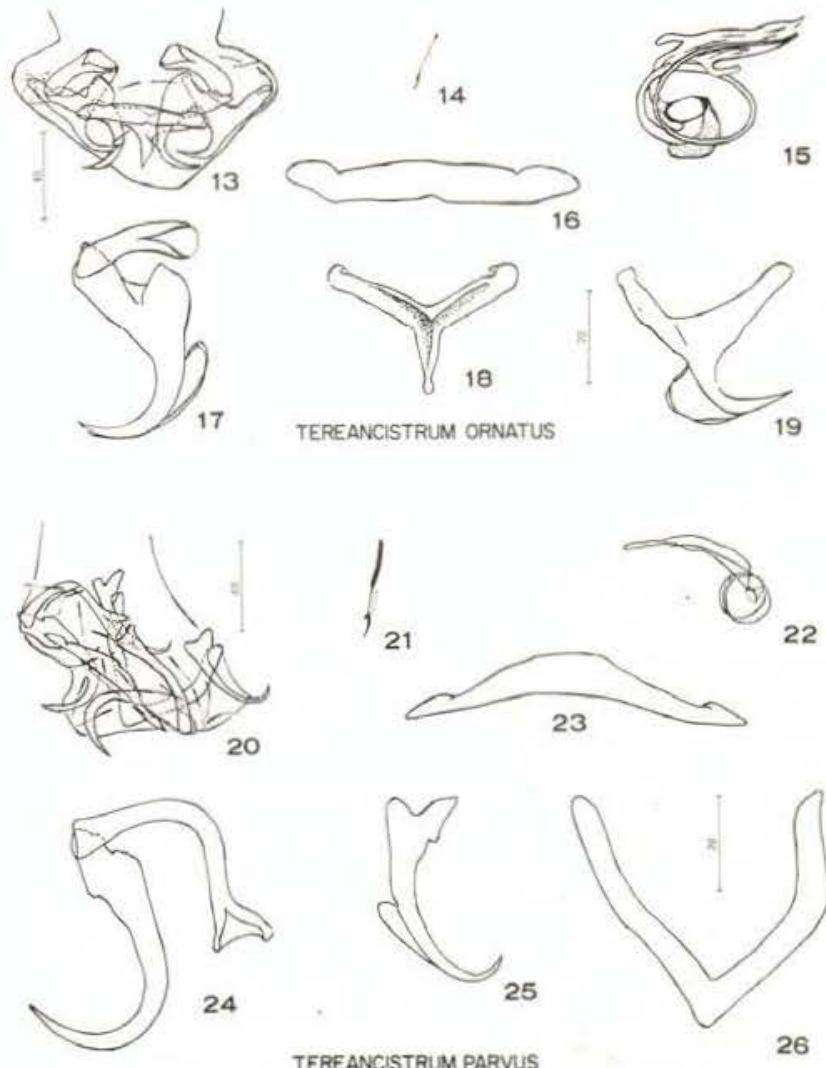

TEREANCISTRUM PARVUS

Plate III: Figures 13-19. Tereancistrum ornatus, sp. n. 13, haptor (ventral). 14, hook. 15, copulatory complex. 16 , ventral bar. 17, ventral anchor and accessory anchor sclerite. 18, dorsal bar. 19, dorsal anchor. Figures 20-26. T. parvus sp. n. 20, haptor (ventral). 21, hook. 22 , copulatory complex. 23, venrtal bar. 24, ventral anchor and accessory anchor sclerite. 25, dorsal anchor. 26 , dorsal bar. All figures are to the same scale $(20 \mu)$ except figures 13 and $20(40 \mu)$.

haptor subhexagonal, 82 long, 92 wide. Hook 21 (18-22) long, with erect thumb, curved shaft, short point, dilated proximal portion of shank; FH loop 0.4 shank length. Ventral anchor 44 long, with well-developed superficial and incipient deep root, broadly curved shaft and point; base 17 wide. Accessory anchor sclerite 53 long, delicate, with small spathulate termination. Dorsal anchor 34 long, with welldeveloped roots, slightly curved shaft, short point; base 14 wide. Ventral bar 69 long. with tapered ends. Dorsal bar 53 long, broadly $\mathrm{V}$ shaped. Cirrus a simple coiled tube of two rings; ring diameter 11. Accessory piece 32 long, flabellate, with terminal blunt projection. Vagina not observed. Vitellaria random throuhout trunk. 
REMARKS

Tereancistrum parvus, $\mathrm{sp}$. n. differs from its closest relative, $T$. ornatus $\mathrm{sp}$. $\mathrm{n}$., in the comparative morphology of the sclerotized haptoral structures (see Figs. 13-26). The specific name is from Latin (parvus $=$ small).

Trinibaculum, gen. n.

DIAGNOSIS

Dactylogyridae: Ancyrocephalinae. Body divisible into cephalic area, trunk, peduncle and haptor. Tegument thin, smooth. Cephalic lobes, head organs, cephalic glands present. Eyes four. Pharynx muscular, grandular; short esophagus bifurcated into two intestinal crura; crura confluent posterior to gonads. Gonads tandem, intercecal; testis postovarian. Seminal vesicle a dilation of vas deferens. Cirrus, accessory piece present. Ovary in posterior half of trunk; seminal receptacle present, uterus delicate; vagina dextroventral; viteliaria well developed. Haptor armed with 14 (7 pairs) hooks, two pairs of anchors; hooks similar, with ancyrocephaline arrangement (Mizelle, 1936). Ventral anchor pair supported by single bar; each dorsal anchor with separate dorsal bar. Parasitic on gills of freshwater fishes.

Type and only species: T. brazilensis, sp. $\mathrm{n}$.

Type host: Brycon melanopterus (Cope).

\section{REMARKS}

This genus differs from all other Ancyrocephalinae by possessing two widely separated simple dorsal bars, a dextroventral vagina, confluent intestinal crura, and intercecal gonads. It is probably closest to Neomurraytrema Tripathi, 1959, from which it is easily differentiated by lacking accessory anchor sclerites on the ventral anchors. The generic name is derived from Latin (trini $=$ in threes + baculum $=$ rod) and refers to the presence of three haptoral bars. This is the only Neotropical genus with three bars.
Trinibaculum brazilensis, $\mathrm{sp} . \mathrm{n}$. (Figs, 27-32)

Host: Matrinchã, Brycon melanopterus (Cope), Characidae.

Location: Gills .

Locality: Januacá Lake, near Manaus, Amazonas, Brasil.

Types: INPA (holotype and paratypes); MZUSP (paratype); USNM (paratypes); UNSM (paratype).

\section{DESCRIPTION (based on 6 specimens)}

Body robust, subtriangular, 459 (398-561) long; greatest width 194 (163-265) in posterior half near haptor. Cephalic margin rounded or with three incipient lobes; head organs, cephalic grands poorly developed. Members of anterior pair of eyes smaller, usually closer

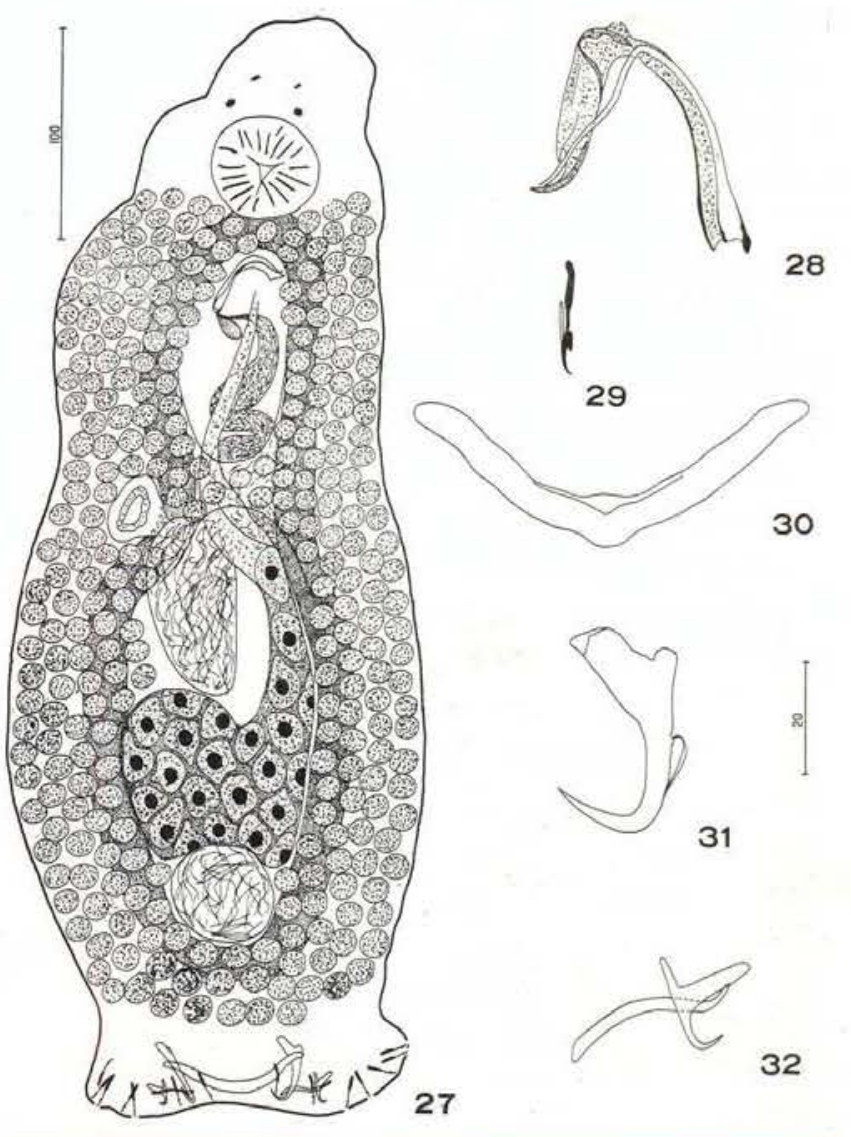

Plate IV: Figures 27-32. Trinibaculum brazilensis, gen. et sp. n. 27, whole mount (ventral). 28, copulatory complex. 29, hook. 30, ventral bar. 31, ventral anchor. 32 , dorsal bar and anchor. All figures are to the same scale $(20 \mu)$ except figure $27(100 \mu)$. 
together than members of posterior pair; component granules ovate, variable in size; accessory granules in anterior trunk and cephalic region. Pharynx subovate, 49 (42-72) wide; mouth directed posteriorly; esophagus short to non-existent. Peduncle short, very broad; haptor trapezoidal, 145 (82-173) wide, 46 (31-61) long. Hooks 18 (17-19) long; each with robust thumb, recurved point, inflated proximal portion of shank; FH loop about $1 / 2$ shank length. Ventral anchor 33 (32-34) long, with well-developed deep and superficial roots, straight shaft and recurved point; base 14 (12-15) wide. Dorsal anchor 17 (15-19) long, with elongate superficial root, spine-shaped deep root, short straight shaft, recurved point; base 12 (10-13) wide. Ventral bar 62 (55-68) long, broadly $\mathrm{V}$ shaped. Dorsal bars similar, sigmoid, 25 (22-31) long. Testis subspherical, 29 in diameter; vas deferens obscured; seminal vesicle a coiled elongate dilation of vas deferens posterior to cirrus; prostatic reservoir small, subovate. Cirrus a simple tube, variably bent, 54 (37-69) long. Accessory piece flabellate, variable, 54 (37-69) long, broadly articulated to proximal portion of cirrus. Ovary irregular, 134 long, 70 wide. Uterus extending along midline; vagina with variably sclerotized wall; seminal receptacle large, ovate, located anterior to ovary. Vitellaria random in trunk except absent in regions of other reproductive organs.

\section{REMARKS}

Trinibaculum brazilensis, gen. et $\mathrm{sp}$. $\mathrm{n}$. is the only species in the genus. The specific name indicates the country from which it was first collected.

\section{SUMÁrIo}

Cinco novas espécies de Monogenoidea (Dactylogyridae: Ancyrocephalinae) foram descritas das brânquias de peixes de água doce da América do Sul: Jainus amazonensis, n. sp.. Tereancistrum kerri, n. gen., n. $\mathrm{sp}$., e Trinibaculum braziliensis, n. gen., n. sp. todas da matrinchā, Brycon melanopterus (Cope) do lago Januacá perto a Manaus, Amazonas, Brasil. Também Tereancistrum ornatus, $\mathrm{n}$. $\mathrm{sp}$. de Prochilodus reticulatus Steindachner do rio Cauca, Juanchito, Cali, Valle, Colômbia, e T. parvus, n. sp. do aracu, Leporinus fasciatus (Bloch) da Amazônia. Dois novos gêneros foram propostos. Tereancistrum, n. gen. foi caracterizado por ter escleritos espatulados como acessórios associados com os ganchos grandes ventrais. Trinibaculum, n. gen. foi estabelecido para as espécies com uma única barra ventral, duas barras dorsais bem separadas, uma vagina dextroventral, os ramos intestinais unidos e gônadas intercecais.

\section{LITERATURE}

KRITSKY, D.C. \& THATCHER, V.E.

1974 - Monogenetic trematodes (Monopisthocotylea: Dactylogyridae) from freshwater fishes of Colombia, South America. J. Helminth., 48: $59-66$

MIZELLE, J.D.

1936 - New species of trematodes from the gills of Illinois fishes. Am. Midl. Nat., 17: 785 806.

Mizeli.E, J.D. \& KLUCKA, A.R.

1953 - Studies on monogenetic trematodes. XIV. Dactylogyridae from Wisconsin fishes. Am. Midl. Nat., 49: $720-733$.

PAPERNA, I.

1969 - Monogetic trematodes of the fish of the Volta basin and South Ghana. Bull. I'I.FA.N., 31 (ser. A): 840-880.

(Aceito para publicação em 18/07/79) 